\title{
MOBILIZAÇÃO COLETIVA E TUTELA \\ JURISDICIONAL DO MEIO AMBIENTE: \\ PRINCIPAIS DESAFIOS À LUZ DA \\ CONSTITUIÇÃO FEDERAL DE 1988
}

\author{
Artur Cortez Bonifácio ${ }^{1}$ \\ Universidade Federal do Rio Grande do Norte (UFRN)
}

$\frac{\text { Jéssyca Cleópatra Yury Soares dos Santos }}{2}$

\section{RESUMO}

A presente pesquisa aborda a mobilização da coletividade e sua relação com a tutela jurisdicional do meio ambiente, com ênfase nos desafios democráticos inferidos a partir das normas constitucionais acerca da matéria ambiental. Apresenta a ação civil pública e ação popular como mecanismos judiciais capazes de interferir nos rumos da preservação ambiental. Discute o papel do Estado Constitucional Ecológico, ao estabelecer como premissa sua atuação inserta nos limites estabelecidos pelo Direito Ambiental. Aborda a pluralidade de intérpretes da Constituição, com o intuito de que estes se mobilizem para promover a proteção ambiental. Debate a democracia participativa sob a perspectiva de determinados doutrinadores. Analisa, ainda, as responsabilidades dos legitimados para a proteção ambiental, de forma crítica, ao elencar a ampliação da educação ambiental como um dos desafios democráticos. Utiliza o método dedutivo, uma vez que serão apresentadas noções gerais sobre o tema e, em seguida, uma análise sobre seus aspectos particulares. A pesquisa bibliográfica com a apresentação da perspectiva de diferentes autores sobre o tema foi a metodologia empregada. Percebeu-se que o Judiciário apresenta sobremaneira relevância, em virtude da crise de representatividade atual, bem como nas incertezas vivenciadas na sociedade contemporânea. Concluiu-se que a mobilização coletiva é um desafio, justamente porque não é encontrada

1 Pós-Doutorado em Ciências Jurídico-Políticas pela Universidade de Lisboa (ULISBOA). Doutorado e Mestrado em Direito do Estado pela Pontifícia Universidade Católica de São Paulo (PUC-SP). Graduado em Direito pela UFRN. Docente da UFRN. Membro cativo da Academia de Letras Jurídicas do Rio Grande do Norte. E-mail: artur_bonifacio@yahoo.com.br

2 Mestranda no Programa de Pós-Graduação em Direito da UFRN. Graduada em Direito pela UFRN. Servidora pública federal. E-mail: jcleosantos@gmail.com 
em seu formato ideal, aguardando a atuação do Poder Público mediante a formulação de suas políticas.

Palavras-chave: desafios democráticos; mobilização coletiva; tutela jurisdicional do meio ambiente.

\section{COLLECTIVE MOBILIZATION AND THE ENVIRONMENTAL JUDICIAL PROTECTION: THE MAIN CHALLENGES IN TERMS OF THE FEDERAL CONSTITUTION OF 1988}

\section{ABSTRACT}

The present research deals with collective mobilization and its relation with the judicial protection of the environment, with emphasis on the democratic challenges inferred from the constitutional norms about the environmental matter. It presents public civil action and popular action as judicial mechanisms as a way of interfering in the direction of environmental preservation. It discusses the role of the Constitutional Ecological State, when establishing as premise its action inserted within the limits established by Environmental Law. Addresses the plurality of interpreters of the Constitution, with the aim of mobilizing them to promote environmental protection. It debates participatory democracy from the perspective of certain scholars. It also analyzes the responsibilities of those legitimized for environmental protection, critically, by listing the expansion of environmental education as one of the democratic challenges. It uses the deductive method, because will be presented general notions about the theme and then an analysis of its particular aspects. The bibliographic research with the presentation of the perspective of different authors on the subject was the methodology employed. It was noticed that the judiciary is extremely relevant due to the current crisis of representativeness, as well as the uncertainties experienced in contemporary society. It was concluded that collective mobilization is a challenge, precisely because it is not found in its ideal format, awaiting the action of the Government through the formulation of its policies.

Keywords: collective mobilization; constitutional protection of the environment; democratic challenges. 


\section{INTRODUÇÃO}

Por que existe a degradação ambiental em tempos de avançado desenvolvimento tecnológico? A história dos sofrimentos humanos causados pela ação da natureza como resposta à desenfreada exploração dos recursos naturais não é suficiente para implantar um novo pensamento sobre o meio ambiente? Não há respostas suficientes em apenas uma área do conhecimento, mas o Direito pode contribuir com a elucidação de tais questionamentos.

No contexto brasileiro, especificamente, a tutela jurisdicional do meio ambiente é um dever imposto ao Poder Público. A coletividade, por sua vez, também apresenta deveres delineados no ordenamento jurídico pátrio. Desvincular esse ente de sua necessária participação no cenário político-jurídico é possibilitar que todas as ações sejam realizadas pelo Estado, que muitas vezes não satisfaz as demandas de grande parte do povo, tendo em vista as diversas atribuições constitucionais que já lhe foram dadas, bem como as questões prioritárias que envolvem o orçamento público.

Se o povo não reivindicar seus direitos em matéria ambiental, o Estado certamente entenderá que esta não é uma área que necessita de grandes investimentos, tornando-se omisso na concretização do direito ao meio ambiente ecologicamente equilibrado, ignorando a previsão constitucional de assegurá-lo.

Desta forma, torna-se fundamental uma ideia de democracia participativa em que o indivíduo escolhe realizar transformações no meio, em virtude do reconhecimento dos benefícios daquela atuação. Ativam-se as atitudes de responsabilidade com o meio ambiente, ao invés de aguardar um posicionamento do Estado em uma democracia apenas representativa.

As referidas atitudes também coordenam uma transformação do pensamento crítico e autônomo sobre a realidade que rodeia determinada pessoa, composta por direitos e deveres na sociedade. É uma modificação, a priori, do pensamento para em seguida a atuação no plano fático, desde as ações mais simples até as mais complexas, que envolvem mobilização de um grande número de pessoas, para a proteção ambiental.

A problemática a ser debatida se refere à essencialidade dessa mobilização, a partir do Direito Ambiental como conjunto de normas que regulam a relação homem-natureza, bem como orienta e limita a atuação do Estado Constitucional Ecológico. Este será apresentado com base na visão das funções estatais, subdivididas em Executivo, Legislativo e Judiciário, 
de acordo com as atribuições que exercem ou deveriam exercer.

Igualmente, serão expostos alguns legitimados na tutela ambiental, com uma análise crítica acerca do cumprimento de suas responsabilidades, e de como estas poderiam ser redimensionadas para alcançarem o desiderato constitucional.

A democracia participativa será abordada sob a perspectiva de determinados doutrinadores, com o intuito de delinear o que já foi estudado acerca do assunto, sem a pretensão de esgotar a temática, até mesmo porque o foco da presente pesquisa está mais relacionado com os desafios democráticos encontrados no cotidiano para que haja uma mobilização popular em termos de tutela ambiental.

Para a demonstração de tais entraves, será apresentada a abordagem anterior ao assunto em si, de modo que será feita uma associação com a Teoria da Constituição, principalmente, acerca das questões democráticas e de como a existência da Constituição é importante para discipliná-las, visando o bem comum, o bem da sociedade como um todo.

\section{BALIZAS PARA A ATUAÇÃO DO ESTADO CONSTITUCIONAL NO ÂMBITO DO DIREITO AMBIENTAL}

O Direito Ambiental é caracterizado por disciplinar a relação entre homem e meio ambiente. Apresenta, igualmente, outras denominações, como Direito do Meio Ambiente e Direito do Ambiente, esta forma considerada menos redundante que "meio ambiente", pois meio já seria o ambiente em que o indivíduo está inserido (BRANDÃO, 2016). José Afonso da Silva acredita, no entanto, que essa redundância apresenta um propósito definido: contribuir com a exatidão do termo escolhido, ressaltando seu sentido nas normas (SILVA, 2010).

Firme-se que o Direito Ambiental "é um Direito que impõe aos demais setores do universo jurídico o respeito às normas que o formam, pois seu fundamento de validade é emanado diretamente da Norma Constitucional" (ANTUNES, 2007, p. 22-23). Há, pois, que se interpretar os demais ramos do Direito a partir de uma visão constitucional, bem como considerando as normas ambientais.

O meio ambiente, por sua vez, nomenclatura adotada no art. $3^{\circ}, \mathrm{I}$, da Lei n. 6.938, de 31 de agosto de 1981, a qual "dispõe sobre a Política Nacional do Meio Ambiente, seus fins e mecanismos de formulação e aplicação, e dá outras providências", é o "conjunto de condições, leis, 
influências e interações de ordem física, química e biológica, que permite, abriga e rege a vida em todas as suas formas".

Ao se escolher utilizar o termo consagrado atualmente, qual seja, Direito Ambiental, anteriormente à utilização para a atuação do Estado Constitucional, sobretudo, em termos ecológicos, imperiosas se mostram breves considerações acerca da relevância desse ramo do Direito para a referida proposta.

Isso se deve ao fato de que o Estado de Direito Ambiental é uma tentativa de responder às demandas da sociedade de risco, garantindo o mínimo existencial ecológico, para o desenvolvimento dos seres humanos em todo o seu potencial, a partir da atenção à qualidade ambiental (MOURA, 2012).

Uma palavra que está intimamente relacionada à sociedade de risco é a incerteza. A ciência é um dos campos em que o referido fenômeno é claramente percebido, bem como no tocante à iminente catástrofe ambiental. Atualmente, novos fatores que não podem ser previstos diminuem a reação estatal, no que diz respeito à gestão pública e aos modos como ela é operacionalizada (MOURA, 2012).

Lidar com esses novos aspectos exige, por parte desse Estado, vislumbrar estratégias inovadoras, o que não significa, em todos os casos, uma garantia de solução das demandas ambientais, pois como o próprio termo indica, a imprevisibilidade não oferece uma percepção de quais serão os novos desafios no desenvolvimento das atividades dos gestores.

Sendo assim, há de se reconhecer que o alcance do direito ao meio ambiente ecologicamente equilibrado pressupõe a atuação do Estado Constitucional Ecológico, também denominado Estado Socioambiental de Direito. Conjugada à participação da sociedade civil, essa atuação do Estado deve se integrar à ampla proteção ambiental, cumprindo seus deveres constitucionais de proteger o ambiente para as presentes e futuras gerações, a saber:

[...] o Estado Constitucional Ecológico é mais do que 'Estado de Direito' ou um 'Estado Democrático', ele está sendo analisado pela necessidade de legitimação do ecologismo, ambientalismo ou qualquer nomenclatura que busque a proteção tenaz e eficaz do meio ambiente, com o olhar focado em um futuro próximo, em que o ambiente será determinante para a sobrevivência digna da humanidade (FERRONATTO et al., 2009, p. 12).

E essa humanidade já convive, nos dias atuais, com os problemas que exigem um novo pensar, um novo agir, indicando que o denominado futuro 
próximo supramencionado denota sinais de que cada vez mais já faz parte do presente.

O Estado em comento apresenta um caráter abstrato, o que não pode se transformar em pretexto para o menosprezo de suas funções. Há, portanto, uma grande relevância no debate de suas premissas, que atuam como parâmetros a serem alcançados (LEITE; FERREIRA, 2010).

Ao partir da premissa de que as funções do Estado Constitucional Ecológico devem ser cumpridas, é inegável que há uma dimensão negativa, uma vez que esse Estado não deve praticar violações ou danos ao meio ambiente. Simultaneamente, deve existir uma atuação positiva, o que remete à noção de Estado Social de uma forma ampliada, reconhecendo que a formulação de políticas públicas é imprescindível para a concretização de direitos com conteúdo ambiental.

Essas políticas públicas devem estar intimamente relacionadas ao exercício da democracia, que, por sua vez, é limitado pela Constituição, para que seja exercido com observância ao ordenamento jurídico como um todo. O Estado Constitucional Ecológico também sofre essas limitações, de modo que, a partir da interpretação constitucional, são estabelecidas referências ou balizas para sua conformação.

Quanto à intervenção do Judiciário nesta seara, destaque-se a atuação do Supremo Tribunal Federal em situação envolvendo a região norte fluminense:

A intervenção do Poder Judiciário, nas políticas públicas de governo, é tema dos mais complexos e que ainda suscita discussões apaixonadas por todos os aspectos que envolve. Na área ambiental, o Supremo Tribunal Federal teve ocasião de examinar recurso extraordinário contra decisão judicial do Tribunal Regional Federal da $2^{\mathrm{a}}$. Região (RJ), dirigida contra o Estado do Rio de Janeiro, determinando que fosse ultimado o Projeto de Estação de Tratamento para despoluição do rio Paraíba do Sul, evitando-se o lançamento de esgoto em estado natural nas águas que abastecem a cidade de Campos de Goytacazes, no norte fluminense. A decisão judicial da Corte Suprema rejeitou a tese de que a ordem judicial constituía verdadeira ingerência em tema da esfera do Poder Executivo, a qual foi dada sem levar em conta os limites financeiros do Estado-membro, impondo-lhe um ônus exacerbado. Eis a ementa: AGRAVO REGIMENTAL NO RECURSO EXTRAORDINÁRIO. CONSTITUCIONAL. AÇÃO CIVIL PÚBLICA. DEFESA DO MEIO AMBIENTE. IMPLEMENTAÇÃO DE POLÍTICAS PÚBLICAS. POSSIBILIDADE. VIOLAÇÃO DO PRINCÍPIO DA SEPARAÇÃO DOS PODERES. NÃO OCORRÊNCIA. PRECEDENTES. 1. Esta Corte já firmou a orientação de que é dever do Poder Público e da sociedade a defesa de um meio ambiente ecologicamente equilibrado para a presente e as futuras gerações, sendo esse um direito transindividual garantido pela Constituição Federal, 
a qual comete ao Ministério Público a sua proteção. 2. O Poder Judiciário, em situações excepcionais, pode determinar que a Administração pública adote medidas assecuratórias de direitos constitucionalmente reconhecidos como essenciais sem que isso configure violação do princípio da separação de poderes. 3. Agravo regimental não provido (STF, Ag. Regimental no Recurso Extraordinário 417.408/ RJ, $1^{\text {a }}$. Turma, Rel. Ministro Dias Toffoli, julgamento em 20/05/2012) (FREITAS, 2014, p. 255, grifo nosso).

Logo, o Direito Ambiental é de fundamental importância para o alcance dessas balizas, porque quando o Estado restringe a atividade do particular, por exemplo, mediante a utilização de seu Poder de Polícia, o faz em nome do bem-estar da coletividade, inclusive, em termos ambientais.

A fiscalização ambiental realizada pelo Estado também demonstra que os poluidores devem se obedecer às normas de Direito Ambiental. Em um exercício hipotético, se não existisse esse conjunto de normas jurídicas na atualidade, com o escopo de disciplinar a utilização dos recursos naturais, os conflitos seriam maiores e até mesmo seria inviável sua resolução, justamente porque cada particular agiria sem maiores preocupações com a coletividade, tampouco com a preservação desse bem jurídico.

Cumpre observar que antes da proteção constitucional nos termos atuais, havia algumas diferenças, pois:

[...] degradação ambiental seria sinônimo de degradação sanitária ou mero apêndice do universo maior da produção e consumo, apresentando-se, portanto, como argumentação de cunho estritamente homocêntrica, com indisfarçável conteúdo economicista e utilitarista (DELAGE, 2009, p. 3).

Existia, portanto, uma percepção do ambiente voltada para o aspecto econômico, sem considerações acerca de direitos fundamentais, dignidade humana, entre outros conceitos firmados, sobretudo, em sede constitucional. Além disso, havia uma preocupação de como servir aos seres humanos, sem dimensionar a relevância de cuidar do ambiente em si, ou seja, pelo que ele representa, independentemente da interferência humana.

A proteção e a conservação do meio ambiente, conforme preconizado pela Constituição da República Federativa do Brasil de 1988 (CRFB) são fatores desejados para a qualidade de vida. Como direito fundamental, traz o direito ao meio ambiente ecologicamente equilibrado, sobretudo, delineado em seu art. 225. Necessária se mostra "a busca da fundamentação deste Ambiente sadio e ecologicamente equilibrado como um Direito Fundamental, integrante da terceira dimensão e balizado pela Dignidade Humana, e em especial como forma de construção de outra feição do 
Estado" (ROCHA; MARQUES, 2016, p. 72).

No que diz respeito à coletividade, a doutrina classifica os direitos de solidariedade ou fraternidade como direitos de terceira dimensão, devido ao fato de serem coletivos ou até mesmo difusos, exigindo uma atuação mundial, em vários momentos, justamente porque envolvem responsabilidades e diversos interesses. No entanto, não há que se desprezar também a dimensão individual de tais direitos em alguns casos concretos, o que impõe a adoção de criativas técnicas que promovam a garantia e proteção destes (SARLET, 2007, p. 58-59).

Importa observar também que, segundo o mesmo dispositivo, o meio ambiente é um bem de uso comum do povo, o que revela sua essência não é somente público, muito menos somente particular. Nesse sentido, "o direito ao meio ambiente sadio como direito fundamental representa dizer que aos cidadãos é conferida a exigência, perante o Estado, de promoção dos direitos da pessoa e dos direitos da vida coletiva e social" (PEREIRA; LIMA; CASAGRANDE, 2013, p. 605).

Outro aspecto importante é que as demandas ambientais são compartilhadas por todo o mundo, de modo que as diretrizes adotadas por determinado governo não devem ser isoladas no que se refere às ações conjuntas em nível global.

Importa compreender que "a transnacionalidade, nesse caso, é corolária da globalização e corresponde a um fenômeno que reconhece a existência de temas que devem ser tratados por todos, independentemente do Estado a que pertencem" (OLSEN; FREITAS, 2017, p. 19). Tal assertiva harmoniza-se com a ideia de interligação entre as nações e de responsabilidade compartilhada entre todos, não somente aquela atribuída aos Estados, embora estes desempenhem um papel indispensável nesse contexto.

Como fator enriquecedor da presente pesquisa, merece destaque, em linhas gerais, a atribuição de deveres em sede constitucional aos Poderes Executivo e Legislativo no Brasil.

No que se refere à formulação de políticas públicas, o Poder Executivo se apresenta mais próximo da população, no sentido de atender às demandas urgentes e absorver as necessidades da população para decidir como será aplicado o orçamento público e quais as ações serão prioritárias na gestão. Tais características se tornam mais nítidas quando são analisadas as conjunturas municipais.

Em termos de atuação administrativa, o Poder de Polícia em suas 
modalidades - preventivo, repressivo e ordenador - é um dever inerente ao Estado. Acrescente-se que "a competência administrativa em matéria ambiental engloba tanto a atividade autorizativa em sentido amplo (licenciamento e autorização ambientais), quanto a atividade de fiscalização" (BIM; FARIAS, 2015, p. 212).

Já no tocante ao Poder Legislativo, reconhece-se que sua atividade, em determinados casos, demanda mais tempo, debate e reflexão acerca dos temas que serão legislados, o que não atende de imediato aos conflitos ambientais, que apresentam também reflexos econômicos e sociais.

Importa compreender que a omissão legislativa também ocasiona uma impossibilidade de proteger direitos na atualidade, o que poderá apresentar consequências para as futuras gerações, uma vez que determinados bens difusos necessitam da ampla atuação das atuais gerações. É, portanto, o agir ético com as gerações vindouras, associado ao agir solidário, sem se desvencilhar da noção do meio ambiente como essencial à humanidade como um todo.

Sendo assim, como uma espécie de filtro à produção legislativa (ao analisar a compatibilidade das normas com a Constituição) e fiscal das atividades administrativas (ao repreender possíveis excessos ou omissões), o Judiciário atua também no contexto de tutela do meio ambiente, solucionando os conflitos de interesses que diariamente são apresentados para que aquele formule a norma de decisão.

Percebe-se, dessa feita, que a tutela jurisdicional satisfativa, célere, enfim, eficiente, propicia o acesso à justiça que impulsiona o desenvolvimento do País. Os demandantes passam a acreditar no Estado Socioambiental, que também pode ser denominado Estado do Bem-Estar Social ou Estado Sustentável, uma vez que suas funções são realmente cumpridas, materializadas em combate à poluição, ao se propor, por exemplo, uma ação civil pública e, a partir desta, resultados favoráveis ao meio ambiente são alcançados. Afinal, renovam as esperanças de que as leis infraconstitucionais e até mesmo a Constituição não são simplesmente palavras sem nenhum valor prático.

Em seguida, será abordada a tutela jurisdicional do meio ambiente e a solidariedade intergeracional. A sociedade necessita que exista essa possibilidade de acionar o Judiciário, tendo em vista, em última análise, o processo de conscientização, além da participação política que esse debate no âmbito da referida função estatal promove, conforme a seguinte lição: 
Note-se que os meios judiciais são, de fato, o último recurso contra a ameaça e degradação ambiental. A sociedade atual exige que as demandas ambientais sejam palco de discussão na via judiciária, pois essa abertura resultará no exercício da cidadania e, consequentemente, maior conscientização (LEITE; FERREIRA, 2010, p. 123).

Contraposta à sensação de impotência mencionada na seguinte ponderação, infere-se que, quando o cidadão participa das decisões, neste caso, em matéria ambiental, há um sentimento de que a legislação é justa e de que é possível, em certa medida, mudar o entorno com o intuito de obter uma qualidade de vida melhor:

[...] o acesso do cidadão e da sociedade civil aos meios de provocação jurisdicional, diminuem a sensação de impotência muitas vezes presentes em grandes ou pequenos desastres ambientais, todos eles de responsabilidade do homem, travestido ora como governo, ora como pessoa jurídica, ou pessoalmente (THEODORO, 2016, p. 83).

Dessa forma, aquele não se sente totalmente vulnerável diante dos atos do governo, de pessoas jurídicas ou de outros indivíduos, porque dispõe de certa faculdade, ou seja, recorrer ou não ao Judiciário.

\section{MOBILIZAÇÃO DA COLETIVIDADE: ESSENCIAL COMO A EXISTÊNCIA DO MEIO AMBIENTE?}

A mídia noticia, com certa frequência, exemplos de pessoas que se comportam em prol do meio ambiente sadio, ao desenvolverem ações isoladas, mas significativas: separar o lixo orgânico, substituir os descartáveis pelos reaproveitáveis e reaproveitar o óleo de cozinha, apenas para citar alguns exemplos (BRAGA, 2016).

Tais ações, no entanto, não resolvem completamente os problemas da atualidade, sendo imperiosas: "ações governamentais para transformar essas condutas de pessoas isoladas ou de parte de comunidades em ações públicas 'macroambientais', estimulando o despertar da consciência ambiental” (BRAGA, 2016, p. 75). Tal despertar seria responsável, em tese, por uma verdadeira revolução sob o ponto de vista do consumo exagerado que é praxe nos dias atuais em muitas culturas. Dessa forma, "a revolução ambiental que se vislumbra significa, dentre outros fatores, cada vez menos consumo compulsivo e mais consumo consciente no sentido de que o "menos pode ser mais" (BRAGA, 2016, p. 76).

Essa redução do consumo excessivo conduz à modificação de valores, ou seja, à eleição do que é mais importante - consumir de forma desmedida 
ou preservar a natureza para garantir a qualidade de vida das presentes e futuras gerações? Logo, "em verdade, a crise que deriva da sociedade atual, que ao longo do tempo se tornou insustentável, não é do ambiente, mas uma crise de valores, o que determina o seu caráter ético" (DUARTE, 2011, p. 187). Não se pode dizer, então, que é uma ação da natureza desvinculada da participação humana para a construção das catástrofes que lhe afetam. O ser humano, com seu comportamento inconsequente, em muitos casos, produz tais desastres.

Antes de apresentar outras ideias, analisar um conceito de mobilização auxilia na clareza e no sentido que se deseja conferir à pesquisa:

A mobilização ocorre quando um grupo de pessoas, uma comunidade ou uma sociedade decide e age com um objetivo comum, buscando, quotidianamente, resultados decididos e desejados por todos. Mobilizar é convocar vontades para atuar na busca de um propósito comum, sob uma interpretação e um sentido também compartilhados. Participar de um processo de mobilização social é uma escolha, porque a participação é um ato de liberdade (TORO; WERNECK, 2004, p. 13).

Essa liberdade também é protegida pela CRFB, quando em seu art. $5^{\circ}$, XVII, e em outros dispositivos, dispõe acerca desse direito.

Um dos desafios democráticos que podem ser observados na sociedade brasileira é a falta de mobilização em grande escala. Percebe-se que há organizações não governamentais, algumas ações da sociedade civil, entretanto, em geral, não há muita exigência da sociedade aos políticos quanto às pautas ambientais. Ao imaginar um possível futuro em que isso ocorre, o resultado é a priorização das matérias políticas, como este ensinamento: "Deveras, na medida em que a classe política passar a ser exigida por seus eleitores sob a inexistência ou ineficácia das políticas de proteção ambiental, esta passará a fazer parte da pauta do dia, será prioridade política de primeira grandeza" (BRAGA, 2016, p. 21).

Nesse sentido, a seguinte observação se mostra pertinente, uma vez que intensifica a necessidade de ampliar o debate público acerca de democracia e da legitimidade das decisões estatais, para que a própria sociedade reflita sobre a imprescindibilidade dessas escolhas, conforme se vê:

A democracia remonta à ideia de participação cidadã na tomada de decisões a respeito das coisas comuns - se não diretamente, ao menos através de representantes. A partir do momento que essa esfera de tomada de decisões se distancia para um plano internacional intocável, ela fica comprometida em sua legitimidade. A proteção do meio ambiente precisa passar por um processo de incorporação cultural, ainda que se saiba que o discurso não atingirá a todos, que atinja a maior parte da população. 
Não se pode desistir desse processo de deliberação pública com argumentos capazes de convencer sobre o valor ético de se preservar o meio ambiente, pois é no espaço do diálogo público que decisões legítimas são tomadas e podem ser efetivamente cumpridas. Decisões políticas que não são reconhecidas só serão cumpridas por meio de coação (OLSEN; FREITAS, 2017, p. 24-25).

Uma das causas da mencionada ausência de mobilização é a falta de informação adequada. Embora os meios de comunicação tenham ampliado a divulgação de dados sobre os rumos das deliberações governamentais, a facilidade de obtenção não significa, necessariamente o uso consciente para alterar o curso do país, principalmente, no viés democrático.

Muitas vezes, as informações são alteradas para a defesa de certos argumentos, que não correspondem necessariamente à realidade. Interesses diversos e conflituosos são divulgados na mídia, o que, em certa medida representa uma série de obstáculos à formação da consciência ambiental e, consequentemente, da mobilização.

Uma reflexão acerca do tema é que "a comunicação no processo de mobilização é dialógica na medida em que não é transferência do saber, mas um encontro de sujeitos interlocutores" (BRAGA; SILVA; MAFRA, 2007, p. 66). Essa assertiva induz à conclusão de que não é somente através do pensamento de único indivíduo ou grupo reduzido que monopoliza a informação ou os pontos de vista, mas a informação deve ser construída mediante um conjunto de percepções, de várias mentes.

Mesmo diante da insatisfação muitas vezes encontrada nas pessoas, tal sentimento não se reverte em atitudes significativas no momento do voto ou de outras formas de intervenção na política, na elaboração de leis ou no acompanhamento das atividades de parlamentares.

Alguns problemas na representatividade e suas consequências são elencados a seguir, de forma cristalina:

Os vícios eleitorais, a propaganda dirigida, a manipulação da consciência pública e opinativa do cidadão pelos poderes e veículos de informação, a serviço da classe dominante, que os subornou, até as manifestações executivas e legiferantes exercitadas contra o povo e a nação e a sociedade nas ocasiões governativas mais delicadas, ferem o interesse nacional, desvirtuam os fins do Estado, corrompem a moral pública e apodrecem aquilo que, até agora, o status quo fez passar por democracia e representação (BONAVIDES, 2001, p. 25-26).

Ressalte-se que a verdadeira democracia não é o simples voto, mas abrange a possibilidade de ter voz, de alterar significativamente o curso das decisões estatais, das resoluções destinadas à coletividade, enfim, à 
proteção do direito individual. Dessa feita, muitos doutrinadores estudam a crise de representatividade, o que realmente ocorre, e que segundo Paulo Bonavides, na lição supramencionada, apresenta diversos problemas, como a manipulação do eleitorado, um obstáculo à democracia participativa em si, a sua autenticidade.

O fato é que existe uma crise representativa na atualidade que pode conduzir à articulação da sociedade civil, independentemente dos Poderes convencionais. "Com a democracia participativa admite-se o exercício do poder por representação, mas com uma intensa participação fiscalizadora da opinião pública e o acréscimo vertiginoso de meios destinados ao debate e à pressão popular [...]" (GÓES, 2011, p. 297). Não se trata, pois, de extinguir o modelo representativo até então conhecido, mas de uma tentativa de fortalecê-los, sem aguardar que toda a responsabilidade pela tutela ambiental recaia sobre o Poder Público. Ratifica esse entendimento a seguinte observação:

Há muitas formas de participação direta do povo na vida política e na direção dos assuntos públicos, que dão configuração concreta à democracia participativa, que não elimina as instituições da democracia representativa. Ao contrário, reforça-a, fazendo com que a relação governo/povo, representante/representado, seja mais estreita e mais dinâmica, propiciando melhores condições para o desenvolvimento de um governo efetivo do povo, pelo povo e em favor do povo (SILVA, 2007, p. 51-52).

Ultrapassando os limites do Brasil, destaque-se que, "como marco ético para um vindouro mundo justo, sustentável e pacífico, a Carta da Terra contém valores e princípios relevantes, incluindo sua interconexão" (BOSSELMANN, 2010, p. 107). Este documento de caráter internacional estabelece princípios para o fortalecimento dos direitos humanos, notadamente, a democracia, como se vê:

13. Fortalecer as instituições democráticas em todos os níveis e proporcionar-lhes transparência e prestação de contas no exercício do governo, participação inclusiva na tomada de decisões, e acesso à justiça.

a. Defender o direito de todas as pessoas no sentido de receber informação clara e oportuna sobre assuntos ambientais e todos os planos de desenvolvimento e atividades que poderiam afetá-las ou nos quais tenham interesse.

b. Apoiar sociedades civis locais, regionais e globais e promover a participação significativa de todos os indivíduos e organizações na tomada de decisões.

c. Proteger os direitos à liberdade de opinião, de expressão, de assembleia pacífica, de associação e de oposição.

d. Instituir o acesso efetivo e eficiente a procedimentos administrativos e judiciais independentes, incluindo retificação e compensação por danos ambientais e pela ameaça de tais danos. 
e. Eliminar a corrupção em todas as instituições públicas e privadas.

f. Fortalecer as comunidades locais, habilitando-as a cuidar dos seus próprios ambientes, e atribuir responsabilidades ambientais aos níveis governamentais onde possam ser cumpridas mais efetivamente.

Quanto à "informação clara e oportuna sobre assuntos ambientais", entende-se um caminho para sua obtenção é a educação ambiental sistemática, das escolas às universidades, dos jornais aos espaços reais de decisões políticas.

Vale salientar que a atuação da família também se mostra fundamental para a conquista de transformações na educação ambiental. Isso significa que "[...] a ação estatal - através da implementação de políticas públicas na área educacional - não pode vir dissociada do comprometimento social com a educação ambiental, a começar pela atuação familiar" (PEREIRA; LIMA; CASAGRANDE, 2013, p. 608).

Há, ainda, institutos brasileiros que, na atualidade, propiciam a participação da sociedade nos rumos das decisões em matérias ambientais. Serão explanados, em linhas gerais: Ação Popular e Ação Civil Pública, porque formam mecanismos para impugnar atos que afetem o meio ambiente.

A proteção ao meio ambiente é veiculada pela ação popular constitucional em obediência à norma presente no art. $5^{\circ}$, LXXIII. Individualmente, o cidadão é o legitimado para sua propositura, ou seja, é um direito subjetivo público, com o intuito de impugnar atos administrativos lesivos.

A Lei n. 4.717/65 isenta de custas e ônus de sucumbência se o autor for vencido ou se ação for julgada improcedente, salvo comprovada má-fé.

O Ministério Público funcionará como fiscal da lei, além de ser permitida sua atuação em determinadas hipóteses.

Como instituto de cidadania e fiscalização da Administração Pública, a ação popular confere aos cidadãos a possibilidade de participar da defesa ambiental, cumprindo, assim, um dever constitucional que repercute nos direitos das presentes e futuras gerações. Além disso, é válido entender que:

A ação popular não tem por escopo único a só fiscalização da conduta dos atos da Administração. Isso porque, ao colocar o meio ambiente como um dos seus objetos transfere ao Poder Público o dever de preservá-lo e protegê-lo, por conta do dispositivo no art. 225, caput, da Constituição Federal. A palavra ato deve, pois, ter um conteúdo mais elástico, abarcando tanto o ato comissivo como o omissivo, porquanto 
é imposto ao Poder Público o dever de prevenção e proteção ao meio ambiente. A finalidade da ação popular trazida pelo art. $5^{\circ}$, LXXIII, da Constituição é anular o ato lesivo, portanto, desconstituir o já praticado. No entanto, se for um ato material propriamente dito, v.g., se uma empresa sem licença para funcionar desrespeitar a norma e poluir o ambiente, a pretensão da ação popular será extirpar o ato que está sendo praticado, de modo a prescrever a abstenção da prática (FIORILLO, 2010, p. 558-559).

Ressalte-se que a ação popular busca anular o ato lesivo, de modo que o ataque aos efeitos do ato consumado deve ser intentado em sede de ação civil pública, como será visto adiante.

A origem ambiental da ação civil pública se encontra na Lei n. 6.938/81, de modo que a Lei n. 7.347/85 disciplina a ação civil pública no âmbito processual, conferindo inovações para essa área.

A sede constitucional está na legitimação do Ministério Público na defesa do meio ambiente exposta no art. 129, III. "Bem por isso, na condição de autêntico porta-voz dos interesses da coletividade na defesa do meio ambiente, posta-se imune a qualquer controle jurisdicional aferidor de adequada representatividade" (MILARÉ, 2009, p. 1076).

Em virtude da diversidade e da relevância dos bens jurídicos protegidos ao se ajuizar a ação civil pública, tais como danos morais e patrimoniais causados ao consumidor, à ordem urbanística, ao patrimônio público e social, existem vários legitimados além do Ministério Público: Defensoria Pública, União, Estados, Distrito Federal e Municípios, autarquia, empresa pública, fundação ou sociedade de economia mista e associação que atenda a determinados requisitos legais. Portanto, a defesa dos direitos difusos não se concentra em apenas um legitimado, o que amplia a apreciação jurisdicional de ameaças ou lesões aos interesses indisponíveis da coletividade.

Cumpre lembrar que o que realmente representa a ação civil pública no contexto histórico e social em que vivemos é um "[...] grande avanço em relação a tudo o que se tinha antes em termos de procedimentos jurisdicionais, de maneira que agora se pode afirmar que o Poder Judiciário, quando devida e regularmente provocado, se apresenta como importante ator na defesa do meio ambiente" (GRANZIERA, 2009, p. 660, grifo nosso).

Desta forma, esse celebrado avanço possibilita uma defesa dos direitos difusos e coletivos vistos sob uma perspectiva diferenciada, até mesmo porque qualquer pessoa física ou jurídica poderá ser ré, o que amplia sobremaneira a atuação do Ministério Público e do próprio Judiciário. 


\section{ANÁLISE CRÍTICA DAS RESPONSABILIDADES PARAA CONSTRUÇÃO DA PROTEÇÃO AMBIENTAL DESEJADA}

A participação popular perpassa pelo modelo da "Sociedade aberta dos intérpretes da Constituição" idealizada por Peter Häberle, tendo em vista que há uma priorização do pluralismo e de informações sobre o ordenamento constitucional, ou seja, é necessário interpretar a Constituição para aplicá-la, de modo que essa interpretação não se restringe aos produtores de normas de decisão ou a determinados grupos de doutrinadores, mas se expande para o povo como um todo (HÄBERLE, 2014, p. 27).

Assim, o mesmo raciocínio se aplicaria aos intérpretes, inclusive, aos legitimados em matéria de tutela ambiental. As responsabilidades destes derivam da interpretação constitucional, que é capaz de atribuir determinadas ações decorrentes até mesmo de princípios implícitos.

A ideia de que a diversidade de legitimados na defesa ambiental em juízo ratifica, sobretudo, a perspectiva de que "deve-se observar o direito ao meio ambiente como forma de preservação da vida e dignidade das pessoas e, ainda, como um bem essencial à qualidade de vida da coletividade, constituindo-se um ponto central dos direitos fundamentais" (FETTBACK, 2009, p. 47).

A partir das atribuições delineadas na Constituição, os legitimados podem agir para a busca do legado ambiental desejado, isto é, a proteção ambiental que se almeja para as presentes e futuras gerações. Assim, a Constituição apresenta-se como figura central de tais realizações, pois a legislação infraconstitucional, necessariamente, deve ser compatível com esta, o que torna adequada a ideia de que a supremacia constitucional suporta, em última análise, a atuação dos legitimados aqui tratados. $\mathrm{O}$ seguinte pensamento ressalta que a participação consiste em um processo, que é originado na Constituição, por esse motivo a necessidade de uma teoria constitucional para as situações em comento:

Constitucionalizar formas e processos de participação é uma tarefa específica de uma teoria constitucional (procedimental). Para conteúdos e métodos, isto se aplica de forma limitada. Fundamentalmente, o processo político deve ser (e deve permanecer), tanto quanto possível, aberto, devendo, também, uma interpretação "diversionista" ter oportunidade de ser sustentada em algum momento. É verdade que o processo político é um processo de comunicação de todos para todos, no qual a teoria constitucional deve tentar ser ouvida, encontrando um espaço próprio e assumindo a sua função enquanto instância crítica (HÄBERLE, 2014, p. 50). 
Em certa medida, quando Paulo Bonavides coteja a democracia participativa com uma teoria da Constituição, em sua modalidade material, aproxima-se da ideia de Häberle, pois ambos acreditam que mencionar a participação é falar sobre teoria da Constituição, consoante pode ser confirmado no pensamento abaixo transcrito:

Não há teoria constitucional de democracia participativa que não seja, ao mesmo passo, uma teoria material da Constituição. Uma teoria cuja materialidade tem os seus limites jurídicos de eficácia e aplicabilidade determinados grandemente por um controle que há de combinar, de uma parte, a autoridade e a judicatura dos tribunais constitucionais e, doutra parte, a autoridade da cidadania popular e soberana exercitada em termos decisórios de derradeira instância (BONAVIDES, 2001, p. 25).

O alcance do legado ambiental desejado, além da ideia de uma sociedade em que todos sejam intérpretes, também necessita de educação ambiental, sem a qual torna-se difícil ou praticamente impossível a realização dos objetivos na matéria aqui abordada. Como um processo contínuo, essa modalidade de educação depende do conhecimento acerca dos problemas que estão ao redor dos indivíduos, para que procurem qualificações adequadas para resolver tais demandas (PEREIRA; LIMA; CASAGRANDE, 2013). São exemplos em que a educação se mostraria imprescindível e transformadora o que aconteceu em Mariana e Brumadinho-MG. Será que a participação popular mudaria o rumo de tais desastres ambientais? E se houvesse uma exigência maior na proteção do meio ambiente oriunda de uma educação voltada para o cenário da exploração de minérios nessa região? É notável que cada cidade brasileira apresenta problemas ambientais peculiares e o sistema educacional, inclusive no âmbito das universidades, deve se adaptar a essa demanda, pois, na maioria das vezes, não é tão simples obter informações sobre a exploração ambiental.

Essa reflexão conduz ao necessário engajamento social, seja do governo, das escolas, das universidades, do cidadão, enfim, da própria coletividade, uma vez que todo esse esforço de políticas públicas bem estruturadas, educação de qualidade voltada para os desafios específicos de cada localidade, bem como o fortalecimento de canais de participação retornam como qualidade de vida e concretização do direito ao meio ambiente ecologicamente equilibrado, cumprindo assim, a Constituição. 


\section{CONCLUSÃO}

A pesquisa apresentou a mobilização coletiva associada à tutela jurisdicional do meio ambiente com seus principais desafios em matéria ambiental. Para tanto, foram expostos determinados mecanismos capazes aptos à tutela jurisdicional, ou seja, a ação civil pública e a ação popular.

Ademais, oEstadoConstitucional foi compreendido sobaperspectivado Direito Ambiental, transformando-se em Estado Constitucional Ecológico ou Socioambiental, guiado pelos limites estabelecidos na Constituição de 1988 e dos outros diplomas legais que formam o ordenamento jurídico brasileiro. Nesse sentido, deve ser a atuação do Judiciário, Legislativo e Executivo. Apesar das considerações acerca destes, ao Judiciário foram destinados os maiores esforços, tendo em vista o debate acerca da tutela jurisdicional do meio ambiente, que também é o foco deste trabalho.

Portanto, como foi amplamente discutido, o Judiciário apresenta uma função de extrema relevância, diante da crise de representatividade percebida na sociedade brasileira, que igualmente está inserida no conceito de sociedade de risco da atualidade, firmada apenas na incerteza e na necessidade de que o Estado Constitucional Ecológico atenda a suas demandas.

Foi justamente essa falta de mobilização, aguardando simplesmente as atividades do Poder Público e suas políticas, que foi problematizada como um dos desafios democráticos. A noção de democracia representativa, investigada, em linhas gerais, desde seu conceito, aliou-se ao princípio constitucional da solidariedade entre gerações, para a resolução desse problema a partir de ditames éticos e do engajamento das presentes e futuras gerações, com a consciência de que a mobilização deve estar atrelada também à ideia de que o legado ambiental desejado dependerá do cumprimento de responsabilidades atribuídas ao legitimado na tutela ambiental. Conforme o raciocínio desenvolvido ao longo deste trabalho, o Supremo Tribunal Federal reconheceu o referido princípio constitucional.

Visto como um direito difuso, o meio ambiente ecologicamente equilibrado foi abordado como essencial à qualidade de vida e relacionado à dignidade humana. Seu alcance depende de outro aspecto, elencado também como desafio democrático, a educação ambiental. A partir desse fator, a exigência, por parte da coletividade, de políticas públicas voltadas à proteção ambiental se tornará cada vez mais comum.

Por fim, cumpre ressaltar que a democracia participativa é um caminho 
para o legado ambiental desejado para as futuras gerações. Obviamente, tal legado deve ser produzido pelas presentes gerações e a Constituição integra esse cenário, com suas normas, que também devem ser interpretadas pelo povo, para combater qualquer tipo de transgressão ao meio ambiente, para honrar a "Constituição Verde", para a verdadeira conquista da qualidade de vida.

\section{REFERÊNCIAS}

ANTUNES, P. B. Direito ambiental. 10. ed. Rio de Janeiro: Lumen Juris, 2007.

BIM, E. F.; FARIAS, T. Competência ambiental legislativa e administrativa. RIL Brasília, Brasília, DF, ano 52, n. 208, p. 203-245, out./dez. 2015. Disponível em: https://www2.senado.leg.br/bdsf/bitstream/handle/ id/517705/001055894.pdf?sequence=1. Acesso em: 10 ago. 2017 .

BONAVIDES, P. Teoria constitucional da democracia participativa: por um direito constitucional de luta e resistência, por uma nova hermenêutica, por uma repolitização da legitimidade. São Paulo: Malheiros, 2001.

BOSSELMANN, K. Direitos humanos, meio ambiente e sustentabilidade. In: SARLET, I. W. (Org.). Estado socioambiental e direitos fundamentais. Porto Alegre: Livraria do Advogado, 2010.

BRAGA, C. S.; SILVA, D. B. C.; MAFRA, R. L. M. Fatores de identificação em projetos de mobilização social. In: HENRIQUES, M. S. (Org.). Comunicação e estratégias de mobilização social. Belo Horizonte: Autêntica, 2007. p. 51-91.

BRAGA, E. Ações ambientais afirmativas: critérios ambientais definidores dos novos parâmetros de financiamento das políticas públicas ambientais. Rio de Janeiro: Lumen Juris, 2016.

BRANDÃO, H. F. O direito ambiental constitucional brasileiro: perspectiva da análise do discurso ecológica. Dissertação (Mestrado em Letras e Linguística) - Faculdade de Letras, Universidade Federal de Goiás, Goiânia, 2016. Disponível em: https://repositorio.bc.ufg.br/tede/ handle/tede/6305. Acesso em: 1 ago. 2017.

BRASIL. [Constituição (1988)]. Constituição da República Federativa do Brasil. Brasília, DF: Presidência da República, 1988. Disponível em: http:// 
www.planalto.gov.br/ccivil_03/Constituicao/ConstituicaoCompilado.htm. Acesso em: 7 jan. 2017.

BRASIL. Lei n. 4.717, de 29 de junho de 1965. Regula a ação popular. Brasília, DF: Presidência da República, 1965. Disponível em: http://www. planalto.gov.br/ccivil_03/leis/L4717.htm. Acesso em: 12 dez. 2016.

BRASIL. Lei $n$. 7.347, de 24 de julho de 1985. Disciplina a ação civil pública de responsabilidade por danos causados ao meio-ambiente, ao consumidor, a bens e direitos de valor artístico, estético, histórico, turístico e paisagístico (VETADO) e dá outras providências. Brasília, DF: Presidência da República, 1985. Disponível em: http://www.planalto.gov. br/ccivil_03/leis/L7347Compilada.htm. Acesso em: 12 dez. 2016.

BRASIL. Lei Ordinária n. 6.938, de 31 de agosto de 1981. Dispõe sobre a Política Nacional do Meio Ambiente, seus fins e mecanismos de formulação e aplicação, e dá outras providências. Brasília, DF: Presidência da República, 1981. Disponível em: http://www.planalto.gov.br/ccivil_03/ leis/L6938compilada.htm. Acesso em: 7 jan. 2017.

BRASIL. Ministério do Meio Ambiente. Carta da Terra. Brasília, DF: MMA, [s.n.]. Disponível em: http://www.mma.gov.br/informma/ item/8071-carta-da-terra. Acesso em: 15 set. 2017.

DELAGE, A. O Poder Judiciário e o direito ambiental. In: II ENCONTRO JURÍDICO REGIONAL - ENJUR, 2., 2009, Passos. Anais [...]. Disponível em: https://bd.tjmg.jus.br/jspui/bitstream/tjmg/678/1/palDA-DIR.pdf. Acesso em: 1 set. 2017.

DUARTE, M. C. S. Meio ambiente sadio: direito fundamental em crise. Curitiba: Juruá, 2011.

FERRONATTO, R. L. et al. Estado constitucional ecológico e o estado socioambiental de direito como formas de assegurar o meio ambiente ecologicamente equilibrado. Diritto \& Diritti, v. 28, p. 01-21, 2009. Disponível em: https://www.diritto.it/pdf_archive/27939.pdf. Acesso em: 15 ago. 2017.

FETTBACK, E. T. L. Cooperativas e tutela coletiva ambiental. Curitiba: Juruá, 2009.

FIORILlO, C. A. P. Curso de direito ambiental brasileiro. 11. ed. São Paulo: Saraiva, 2010. 
FREITAS, V. P. A desejada e complexa conciliação entre desenvolvimento econômico e proteção do meio ambiente no Brasil. Revista Direito Ambiental e Sociedade, Caxias do Sul, v. 4, n. 1, p. 235-263, 2014. Disponível em: www.ucs.br/etc/revistas/index.php/direitoambiental/ article/download/3692/2115. Acesso em: 1 set. 2017.

GÓES, R. T. Jurisdição democrática: uma visão procedimentalista para a tutela substancial dos direitos. Revista Direito e Liberdade - ESMARN, Natal, v. 13, n. 2, p. 291-312, jul.-dez. 2011. Disponível em: http://www. esmarn.tjrn.jus.br/revistas/index.php/revista_direito_e_liberdade/article/ view/441/446. Acesso em: 5 out. 2017.

GRANZIERA, M. L. M. Direito ambiental. São Paulo: Atlas, 2009.

HÄBERLE, P. Hermenêutica Constitucional - a sociedade aberta de intérpretes da Constituição: contribuição para interpretação pluralista e "procedimental" da Constituição. Revista Direito Público. Brasília, DF, v. 11, n. 60, nov.-dez. 2014. Disponível em: https://www.portaldeperiodicos. idp.edu.br/direitopublico/article/view/2353/1204. Acesso em: 15 set. 2017.

LEITE, J. R. M.; FERREIRA, M. L. P. C. Estado de direito ambiental no Brasil: uma visão evolutiva. In: FARIAS, T.; COUTINHO, F. S. N. (Coords.). Direito ambiental: o meio ambiente e os desafios da contemporaneidade. Belo Horizonte: Fórum, 2010. p. 115-129.

MILARÉ, É. Direito do ambiente: a gestão ambiental em foco. 6. ed. São Paulo: Revista dos Tribunais, 2009.

MOURA, A. A. G. A sociedade de risco e o desenvolvimento sustentável: desafios à gestão ambiental no Brasil. Revista Direito \& Práxis - UERJ, Rio de Janeiro, v. 3, n. 2, p. 29-49, 2012. Disponível em: http://www.epublicacoes.uerj.br/index.php/revistaceaju/article/view/3063/3340. Acesso em: 1 set. 2017.

OLSEN, A. C.; FREITAS, V. P. Resgate do ideal democrático no direito ambiental planetário. Campo Jurídico - Revista de Direito Agroambiental e Teoria do Direito, Barreiras, v. 5, n.1, p. 9-34, jun. 2017. Disponível em: http://fasb.edu.br/revista/index.php/campojuridico/article/view/203/159. Acesso em: 2 set. 2017.

PEREIRA, L. T. M.; LIMA, F. R.; CASAGRANDE, A. Educação ambiental: a consolidação de um conceito advindo de uma realidade 
contemporânea. Revista Eletrônica do Curso de Direito da UFSM, Santa Maria, v. 8, p. 603-610, 2013. Disponível em: https://docs.google.com/ viewerng/viewer?url=https://periodicos.ufsm.br/revistadireito/article/ viewFile/8386/5077. Acesso em: 1 set. 2017.

ROCHA, L. S.; MARQUES, C. A. M. Os direitos humano-fundamentais e a proteção ambiental: risco, consumo e racionalidade ambiental. Revista Jurídica Científica do Centro de Ciências Jurídicas da Universidade Regional de Blumenau (CCJ/FURB), Blumenau, v. 20, n. 42, p. 67-84, maio-ago. 2016. Disponível em: http://gorila.furb.br/ojs/index.php/ juridica/article/view/5870/3419. Acesso em: 1 set. 2017.

SARLET, I. W. A eficácia dos direitos fundamentais. 8. ed. Porto Alegre: Livraria do Advogado, 2007.

SILVA, J. A. Poder constituinte e poder popular: estudos sobre a Constituição. São Paulo: Malheiros, 2007.

SILVA, J. A. Direito ambiental constitucional. 8. ed. atual. São Paulo: Malheiros, 2010.

THEODORO, M. A. Tutela processual do meio ambiente no Brasil. Revista de Direito Ambiental e Socioambientalismo, Curitiba, v. 2, n. 2, p. 68-85, jul.-dez. 2016. Disponível em: http://indexlaw.org/index.php/ Socioambientalismo/article/view/1616/2086. Acesso em: 9 set. 2017.

TORO, J. B. WERNECK, N. M. D. Mobilização social: um modo de construir a democracia e a participação. Belo Horizonte: Autêntica, 2004.

Artigo recebido em: 25/02/2019.

Artigo aceito em: 16/09/2019.

\section{Como citar este artigo (ABNT):}

BONIFÁCIO, A. C.; SANTOS, J. C. Y. S. Mobilização coletiva e tutela jurisdicional do meio ambiente: principais desafios à luz da Constituição Federal de 1988. Veredas do Direito, Belo Horizonte, v. 17, n. 37 , p. 191-212, jan.-abr. 2020. Disponível em: http://revista.domhelder. edu.br/index.php/veredas/article/view/1494. Acesso em: dia mês. ano. 